\title{
Measurement of Compaction Degree of Aeolian Sand Roadbed Formed by Dry Compaction with Immersion Plus Cutting Ring Method \\ JIN Chang-ning ${ }^{1, a}$ \\ ${ }^{1}$ Foshan University, Foshan, Guangdong, 528000, China \\ axjjcnalt@163.net
}

\begin{abstract}
Keyword: road engineering, density, cutting ring method, aeolian sand, powdery clay particles Abstract. In order to discuss the application scope of measurement of compaction degree of aeolian sand roadbed formed by compaction with immersion plus cutting ring method, powdery clay particles with different content are blended into the aeolian sand from the Gurbantunggut desert for testing. The results show that there is both expansion and sinking of the deformation of the aeolian sand with different compaction degree and the content of the powdery clay particles after immersion, but most of the deformation quantity is not significant. The measured results of the cutting ring method are quite volatile, and there are special circumstances, for example the difference is larger when the degree of compaction is lower and the content of the powdery clay particles is higher; but most of the average values are within the true value range or have a small difference, especially when the compaction degree is higher and powdery clay particles content is "moderate", most of them are within $0.015 \mathrm{~g} / \mathrm{cm}^{3}$. Taking into account that the compaction degree of the detection objects in actual work is generally higher, and the time from the beginning of the immersion to completion of the test is relatively short, on the basis of appropriate increase of parallel test, the test results of aeolian sand roadbed formed by dry compaction can basically meet the needs of the project.
\end{abstract}

\section{Introduction}

The cohesion of dry aeolian sand is basically zero, which is bulk granular, so the conventional methods: sand filling method, cutting ring method, wax seal method, irrigation method cannot be used for the measurement of its density (compaction degree). Some scholars have proposed immersion plus cutting ring method[1], and the experimental results show that when the compaction degree of the aeolian sand is more than $90 \%$, the volume change caused by immersion of the dry sand is very small; The wet sand dry density measured by the cutting ring method can characterize the dry sand dry density before immersion, which can meet the needs of highway engineering in terms of accuracy. On the basis of this, this paper will further discuss the effects of the change of powdery clay particles content in the aeolian sand on this method. The powdery clay particles content is the component which can most easily change and has the greatest change in aeolian sand. The reason is that when there is wind erosion, the fine textured materials will be blown away in the form of dust; after the dunes are fixed, the dust on the surface can form the sand crust, and can enter the sand layer inside with the infiltration of rain. In the same desert around the world, the content of powdery clay particles is generally relatively lower in the moving dunes, higher in semi-mobile and semi-fixed dunes, and highest in the fixed dunes[2,3]. Therefore, the rapid, simple and adaptable method for measuring the density of dry aeolian sand will play an active role in ensuring the construction quality of highway subgrade formed by dry compaction process in desert area.

\section{Introduction to the testing program}

Sample taking, preparation and molding. Take the relatively pure aeolian sand (number A) from the moving dunes on the hinterland of the Gurbantunggut Desert, and silt from the silt flat ground between the dunes (number $\mathrm{Z}$, only use the part which is less than $0.074 \mathrm{~mm}$ ). Blend the two materials in different proportions to obtain test samples with different content of powdery clay particles. It can be seen from figure 1 that, when the powdery clay particles content is more than $40 \%$, the dry compaction effect is not significant, the compaction dry density with the best water 
content has been significantly greater than the compaction dry density with dry air, so the maximum value of the powdery clay particles content of the test sample is limited to $40 \%$ (Table 1). From figure 1, we can know the standard dry density with dry air (Table 2). Then, use the vibrating tamper to mold the sample in a special large test tube (diameter is $45 \mathrm{~cm}$, height is $30 \mathrm{~cm}$, figure 2), the total height of the molding should be controlled at about $25 \mathrm{~cm}$, and control the degree of compaction at about $85 \%, 90 \%, 95 \%$ and $100 \%$ by means of adjusting the tamper.

Table 1 Particle size composition of the test sample

\begin{tabular}{|c|c|c|c|c|c|c|c|c|c|c|c|c|c|}
\hline \multirow{2}{*}{$\begin{array}{c}\text { Sample } \\
\text { No }\end{array}$} & \multirow{2}{*}{$\begin{array}{c}\text { Powdery } \\
\text { clay } \\
\text { particles } \\
\text { content[\%] }\end{array}$} & \multicolumn{12}{|c|}{ Particle size $[\mathrm{mm}] \sim$ Passing rate $[\%]$} \\
\hline & & 1.5 & 1 & 0.5 & 0.25 & 0.15 & 0.1 & 0.074 & 0.05 & 0.02 & 0.01 & 0.005 & 0.002 \\
\hline $\mathrm{A}$ & 11.9 & 100 & 96.1 & 83.1 & 55.3 & 34.2 & 22.8 & 11.9 & 9.5 & 5.3 & 1.4 & 1.1 & 1.1 \\
\hline B & 15.0 & 100 & 96.2 & 83.7 & 56.9 & 36.5 & 25.5 & 15.0 & 11.8 & 6.3 & 2.0 & 1.5 & 1.3 \\
\hline $\mathrm{C}$ & 20.0 & 100 & 96.5 & 84.7 & 59.4 & 40.2 & 29.9 & 20.0 & 15.4 & 8.0 & 3.0 & 2.1 & 1.6 \\
\hline $\mathrm{D}$ & 25.0 & 100 & 96.7 & 85.6 & 61.9 & 44.0 & 34.3 & 25.0 & 19.1 & 9.6 & 4.0 & 2.8 & 1.9 \\
\hline $\mathrm{E}$ & 30.0 & 100 & 96.9 & 86.6 & 64.5 & 47.7 & 38.7 & 30.0 & 22.7 & 11.3 & 5.0 & 3.4 & 2.1 \\
\hline $\mathrm{F}$ & 35.0 & 100 & 97.1 & 87.5 & 67.0 & 51.5 & 43.0 & 35.0 & 26.4 & 13.0 & 5.9 & 4.1 & 2.4 \\
\hline G & 40.0 & 100 & 97.3 & 88.5 & 69.6 & 55.2 & 47.4 & 40.0 & 30.0 & 14.6 & 6.9 & 4.7 & 2.7 \\
\hline $\mathrm{Z}$ & 100.0 & 100 & 100 & 100 & 100 & 100 & 100 & 100 & 73.9 & 34.5 & 18.7 & 12.4 & 6.2 \\
\hline
\end{tabular}

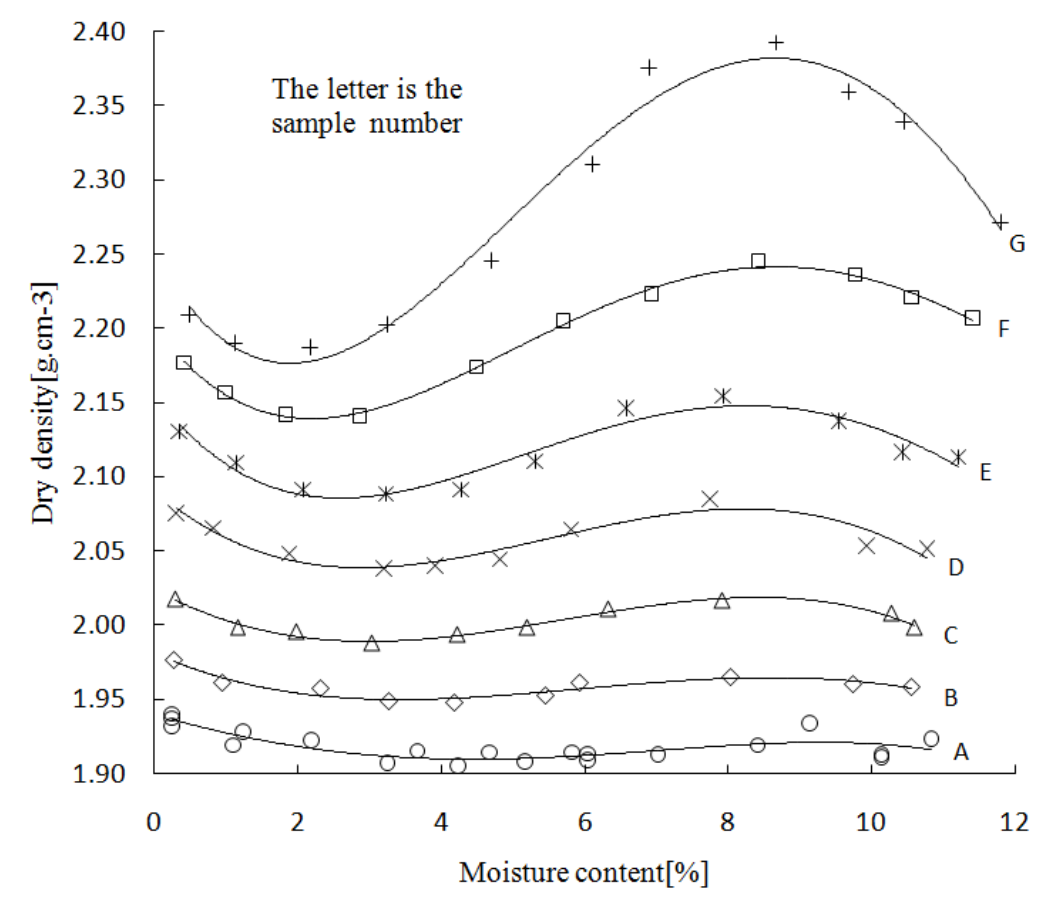

Fig. 1 Compaction curve of the test sample

Table 2 Standard dry density of the test sample when it is compacted in air-dried state

\begin{tabular}{cccccccc}
\hline Sample No & A & B & C & D & E & F & G \\
\hline Standard dry density $\left[\mathrm{g}^{-\mathrm{cm}^{-3}}\right]$ & 1.937 & 1.977 & 2.018 & 2.075 & 2.131 & 2.177 & 2.209 \\
\hline
\end{tabular}

Sample immersion and deformation observation. Choose a piece of thin, exquisite and previous non-woven geotextile, cut it into a round shape with diameter of $450 \mathrm{~mm}$, immerse it into water, and then take put and unfold; After there is no water dripping, put it carefully on the surface of molding sample, and then gently wipe it with a small wood float to ensure that the entire geotextile can more closely contact with the sample surface, instead of using large strength to change the density of the test sample. Afterwards, place a porous plate with fine holes on the geotextile and install a dial indicator on the strut on the edge of the porous plate (Figure 3). 


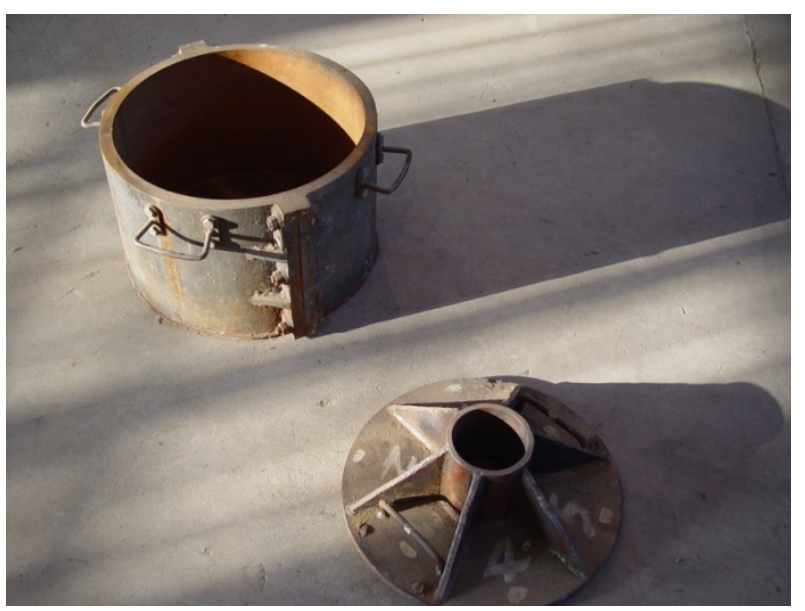

Fig. 2 Special large compaction tube

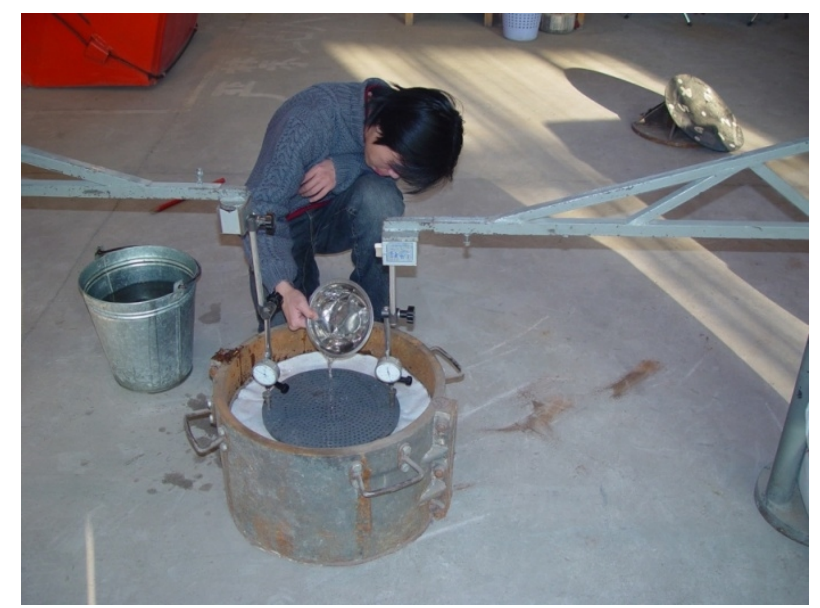

Fig. 3 Deformation observation device

After the test starts, watering and timing should be synchronous. When watering, use a sprinkling can to slowly and evenly sprinkle the water on the porous plate and geotextile, to form a complete thin water layer on the geotextile surface to ensure uniform infiltration (Figure 3). In terms of timing, read the dial indicator according to the specific time, and timing closing is unified for 1080 minutes, when the deformation of various samples have kept stable or nearly stable.

It can be known through analysis of the results of the compaction test that there is capillary water of the sample about when moisture content is about $1 \%$ to $4 \%$, which manifests as the first dry density low value in the multimodal compaction curve. And there is gravity water when the water content is about $9 \%$, which manifests as the second dry density high value in the multimodal compaction curve (the first appears when the water content is close to zero, the samples A and B have special concave curve, so there is no second dry density high value, but it is close to saturation when the water content reaches 9\%). Given this, taking into account that water loss in the test process and a certain amount of gravity water can accelerate the wetting speed, use water content of $10 \%$ to calculate the total water amount required for a certain test.

Density measurement. After completing the deformation observation, remove the dial indicator, take out the porous plate and geotextile, and carefully scrape sand layer of about $2 \mathrm{~cm}$ on the surface of the test sample, and then perform density measurement according to the cutting ring method in Test Method of Soils for Highway Engineering. In order to improve the measurement accuracy, cutting ring with big volume is chosen, which is $200 \mathrm{~cm}^{3}$ (diameter of $70 \mathrm{~mm}$ ).

\section{Test results and analysis}

Deformation observation. The test results are shown in Table 3 and Figure 4. It can be seen:

1) There is both expansion and sinking of the deformation after the immersion of the test sample. No matter what type, it is rapid in the initial stage, and then slower and slower. Except those with small amount of deformation (such as the amount of expansion or sinking is less than $0.1 \%$ ), comparing the deformation amount of 60 minutes with that of 1080 minutes, when the degree of compaction is less than $95 \%$ or so, the former can reach more than $90 \%$ of the latter; and when the degree of compaction is more than $95 \%$, the former can reach more than $80 \%$ of the latter. The reason is that the well-drained sandy soil can complete deformation with a faster speed[4,5].

2) When the content of powdery clay particles is relatively low (such as sample A and B), it is obviously manifested that: there is sinking when the compaction degree is low, and the amount of sinking is large; and when the compaction degree is high, though there is also sinking, the amount of sinking significantly reduces, which can be basically negligible. It indicates that the infiltration of water can lead to the movement of sand particles, making the loose sand dense, based on which some of China's desert areas use sluicing method for the construction of aeolian sand roadbed[6].

3) When the content of powdery clay particles is high (such as sample G), except the sinking when there is low degree of compaction (but the sinking range has been significantly reduced), most 
are manifested as expansion, and also manifested that the amount of expansion will become larger and larger as the degree of compaction is getting higher and higher. The reason is that the more and more powdery clay particles have more and more obvious effects; and powder clay particles, especially the clay particles have strong hydrophilicity, which will expand when encountering water.

Table 3 Test sample $(\mathrm{A} \sim \mathrm{E})$ expansion [/\%] after immersion

\begin{tabular}{cccccc}
\hline & Degree of compaction[\%] & 83.63 & 88.95 & 94.20 & 99.34 \\
$\mathrm{~A}$ & $60 \mathrm{~min}$ & -3.17 & -1.60 & -0.46 & -0.14 \\
& $1080 \mathrm{~min}$ & -3.52 & -1.78 & -0.59 & -0.19 \\
\hline \multirow{3}{*}{$\mathrm{B}$} & Degree of compaction[\%] & 84.50 & 90.62 & 95.09 & 99.81 \\
& $60 \mathrm{~min}$ & -2.35 & -1.01 & -0.27 & -0.08 \\
& $1080 \mathrm{~min}$ & -2.63 & -1.11 & -0.31 & -0.10 \\
\hline \multirow{3}{*}{$\mathrm{C}$} & Degree of compaction[\%] & 83.72 & 89.28 & 96.30 & 99.85 \\
& $60 \mathrm{~min}$ & -2.05 & -0.97 & -0.18 & 0.04 \\
& $1080 \mathrm{~min}$ & -2.29 & -1.06 & -0.19 & 0.05 \\
\hline \multirow{3}{*}{$\mathrm{D}$} & Degree of compaction[\%] & 84.64 & 89.53 & 95.02 & 99.44 \\
& $60 \mathrm{~min}$ & -1.49 & -0.73 & -0.09 & 0.23 \\
& $1080 \mathrm{~min}$ & -1.65 & -0.79 & -0.13 & 0.26 \\
\hline \multirow{2}{*}{$\mathrm{E}$} & Degree of compaction[\%] & 85.11 & 90.35 & 94.80 & 99.67 \\
& $60 \mathrm{~min}$ & -0.98 & -0.29 & 0.14 & 0.49 \\
& $1080 \mathrm{~min}$ & -1.11 & -0.37 & 0.18 & 0.54 \\
\hline \multirow{2}{*}{$\mathrm{F}$} & Degree of compaction[\%] & 84.19 & 89.43 & 95.40 & 98.94 \\
& $60 \mathrm{~min}$ & -0.72 & -0.07 & 0.50 & 0.90 \\
& $1080 \mathrm{~min}$ & -0.81 & -0.12 & 0.56 & 1.01 \\
\hline \multirow{2}{*}{$\mathrm{G}$} & Degree of compaction[\%] & 85.41 & 90.60 & 95.33 & 98.53 \\
& $60 \mathrm{~min}$ & -0.29 & 0.33 & 0.84 & 1.38 \\
& $1080 \mathrm{~min}$ & -0.31 & 0.38 & 0.96 & 1.58 \\
\hline
\end{tabular}

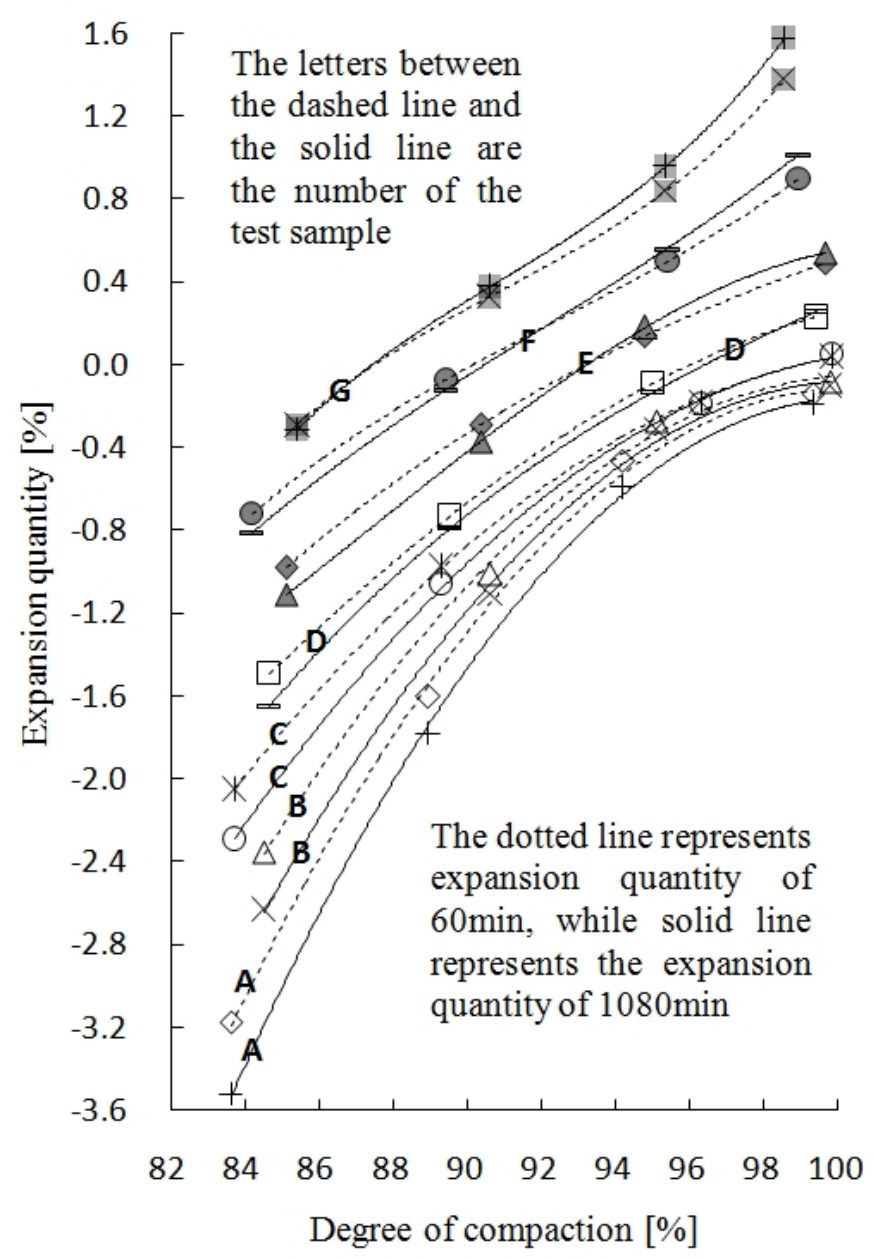

Fig. 4 Expansion quantity of the test sample with different degrees of compaction after immersion 
4) Influenced by the above two factors, that has relatively small deformation and its change with different compaction degrees, that is, has relatively gentle the curve in Figure 4, is not the pure aeolian sand (such as sample A), nor the silty fine sand (such as sample G), but those with relatively "moderate" powdery clay content (such as the sample C, D and E).

It can be seen from Figure 1 that, the compaction curve of those samples with relatively "moderate" powdery clay particles content, such as the sample C, D and E, has three distinct characteristics: first, the effect of dry compaction is significant; second, it is obviously the bimodal pattern; third, the dry density of the compacted molding with air drying is the largest or close to the maximum. The reason is that the pure aeolian sand has larger degree of porosity, the increased powdery clay particles first fill in the holes with skeleton structure composed of sand, which are scattered at very low water content, having little effect on the mutual closeness of the dry powdery clay particles, that is, having little effect on the dry compaction characteristics, but increasing the dry density. With the increase of the powdery clay particles content, the holes in the aeolian sand are gradually filled, and the dry density of the compaction modeling can reach the maximum; Thereafter, the increased content of powdery clay particles will gradually destroy the skeleton structure composed of sand, resulting in pressing of the "excess powder particles", while the superficially active powdery clay particles (especially the clay particles) are difficult to produce cohesion to be compact in the state of dryness, and the dry density of the compaction modeling will gradually decline [7,8].

For the same reason, coupled with the immersion, if there is "extra space" when the powdery clay particles in the holes of the skeleton structure composed of sand expand, the expansion force will not be applied to the skeleton structure; The excessive powdery clay particles can produce expansion force to squeeze the skeleton structure, and the more the powdery clay particles content is, the greater the expansion pressure will be, which will cause that the deformation after immersion is relatively gentle when powdery clay particles content is relatively "moderate"[9].

5) It is required in the Test Method of Soils for Highway Engineering on the density test that the difference in the two parallel measurements shall not be greater than $0.03 \mathrm{~g} / \mathrm{cm}^{3}[10]$. If the dry density of the sample calculated by is $2.0 \mathrm{~g} / \mathrm{cm}^{3}$, the error is $\pm 1.5 \%$. After immersion for 1080 minutes, the deformation of most of the samples is within this range, but there are only two exceptions: one is that the degree of compaction and powdery clay particles content are low, which is manifested as too large amount of sinking; Another is that degree of compaction and powdery clay particles content are higher, which is manifested as too large amount of expansion. Taking into account that the time from the beginning of immersion to the completion of the test is not very long ( generally within 30 minutes), and the detection objects have higher degree of compaction, so it can be considered that immersion measures have have little influence on its density, but it is not absolute.

Density determination. After completing the deformation observation, the density is measured with cutting ring method, and the results are shown in Table 4 . The total error is about \pm $0.5 \%$ due to the existence of the measurement error of the compaction tube diameter, the measurement error of the sample modeling height, the weighing error of the sample and the measurement error of water content, the maximum and the minimum values of dry density at the time of molding, and the maximum and minimum values of dry density after immersion are respectively the range limits of the truth values that are determined after considering the error. It can be seen:

1) The measured results of the cutting ring method are quite volatile, and the measured density difference of the same sample can be above $0.1 \mathrm{~g} / \mathrm{cm}^{3}$, but the most are still within $0.075 \mathrm{~g} / \mathrm{cm}^{3}$. The main reasons are as follows: first, the cohesion of wetted aeolian sand is not large, and the external disturbances still have a certain impact; second, compared with silty soil or clay, aeolian sand's "rough" surface will affect the authenticity of its volume. This accidental error can be solved by increasing the number of parallel measurement.

2) When the degree of compaction is low, such as about $85 \%$, the measurement results of the cutting ring method are generally too large, often larger than the truth value of dry density after 
immersion, and sometimes even much larger, which is larger than $0.03 \mathrm{~g} / \mathrm{cm}^{3}$; At the same time, parallel tests also have large volatility, and the extreme difference is mostly above $0.1 \mathrm{~g} / \mathrm{cm}^{3}$. The reason is that loose sand can be easily compacted in the measurement process, indicating that this method is not suitable for this.

Table 4 Measurement of density after immersion

\begin{tabular}{|c|c|c|c|c|c|c|c|c|c|c|c|c|c|}
\hline \multirow{2}{*}{ 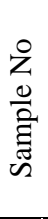 } & \multirow[t]{2}{*}{$\begin{array}{c}\text { Dry } \\
\text { density } \\
{[\%]}\end{array}$} & \multicolumn{2}{|c|}{$\begin{array}{c}\text { The dry density } \\
\text { at the time of } \\
\text { molding } \\
{\left[\mathrm{g} \cdot \mathrm{cm}^{-3}\right]}\end{array}$} & \multicolumn{2}{|c|}{$\begin{array}{l}\text { Dry density } \\
\text { after } \\
\text { immersion } \\
{\left[{\left.\mathrm{g} . \mathrm{cm}^{-3}\right]}\right.} \\
\end{array}$} & \multicolumn{8}{|c|}{$\begin{array}{l}\text { Measurement of dry density (from small to large) } \\
\text { with cutting ring method }\left[\mathrm{g} . \mathrm{cm}^{-3}\right]\end{array}$} \\
\hline & & $\min$ & $\max$ & $\min$ & $\max$ & 1 & 2 & 3 & 4 & 5 & 6 & Average & $\begin{array}{l}\text { Extreme } \\
\text { difference }\end{array}$ \\
\hline \multirow{4}{*}{ A } & 83.63 & 1.612 & 1.628 & 1.671 & 1.687 & 1.596 & 1.654 & 1.674 & 1.683 & 1.737 & 1.740 & 1.681 & 0.144 \\
\hline & 88.95 & 1.714 & 1.732 & 1.745 & 1.763 & 1.705 & 1.705 & 1.715 & 1.718 & 1.719 & 1.779 & 1.724 & 0.074 \\
\hline & 94.20 & 1.816 & 1.834 & 1.826 & 1.845 & 1.801 & 1.807 & 1.814 & 1.858 & 1.860 & 1.867 & 1.835 & 0.066 \\
\hline & 99.34 & 1.915 & 1.934 & 1.918 & 1.938 & 1.913 & 1.916 & 1.923 & 1.930 & 1.934 & 1.936 & 1.925 & 0.023 \\
\hline \multirow{4}{*}{ B } & 84.50 & 1.662 & 1.679 & 1.707 & 1.724 & 1.621 & 1.747 & 1.776 & 1.795 & 1.802 & 1.806 & 1.758 & 0.185 \\
\hline & 90.62 & 1.783 & 1.801 & 1.803 & 1.821 & 1.767 & 1.797 & 1.810 & 1.841 & 1.848 & 1.857 & 1.820 & 0.090 \\
\hline & 95.09 & 1.871 & 1.889 & 1.876 & 1.895 & 1.896 & 1.897 & 1.900 & 1.903 & 1.912 & 1.924 & 1.905 & 0.028 \\
\hline & 99.81 & 1.963 & 1.983 & 1.965 & 1.985 & 1.949 & 1.961 & 1.963 & 1.963 & 1.967 & 1.990 & 1.966 & 0.041 \\
\hline \multirow{4}{*}{$\mathrm{C}$} & 83.72 & 1.681 & 1.698 & 1.720 & 1.738 & 1.661 & 1.717 & 1.725 & 1.786 & 1.810 & 1.813 & 1.752 & 0.152 \\
\hline & 89.28 & 1.793 & 1.811 & 1.812 & 1.830 & 1.776 & 1.778 & 1.813 & 1.819 & 1.856 & 1.870 & 1.819 & 0.094 \\
\hline & 96.30 & 1.934 & 1.953 & 1.937 & 1.957 & 1.918 & 1.924 & 1.946 & 1.947 & 1.947 & 1.954 & 1.939 & 0.036 \\
\hline & 99.85 & 2.005 & 2.025 & 2.004 & 2.024 & 1.995 & 1.998 & 2.032 & 2.035 & 2.039 & 2.044 & 2.024 & 0.049 \\
\hline \multirow{4}{*}{ D } & 84.64 & 1.747 & 1.765 & 1.777 & 1.795 & 1.716 & 1.763 & 1.781 & 1.813 & 1.848 & 1.869 & 1.798 & 0.153 \\
\hline & 89.53 & 1.848 & 1.867 & 1.863 & 1.882 & 1.834 & 1.844 & 1.845 & 1.856 & 1.868 & 1.917 & 1.861 & 0.083 \\
\hline & 95.02 & 1.962 & 1.982 & 1.964 & 1.984 & 1.966 & 1.973 & 1.981 & 1.985 & 1.993 & 2.000 & 1.983 & 0.034 \\
\hline & 99.44 & 2.053 & 2.074 & 2.048 & 2.068 & 2.047 & 2.057 & 2.058 & 2.066 & 2.069 & 2.082 & 2.063 & 0.035 \\
\hline \multirow{4}{*}{ E } & 85.11 & 1.805 & 1.823 & 1.825 & 1.843 & 1.787 & 1.793 & 1.817 & 1.833 & 1.852 & 1.910 & 1.832 & 0.123 \\
\hline & 90.35 & 1.916 & 1.935 & 1.923 & 1.942 & 1.909 & 1.910 & 1.933 & 1.938 & 1.942 & 1.970 & 1.934 & 0.061 \\
\hline & 94.80 & 2.010 & 2.030 & 2.006 & 2.027 & 1.982 & 1.992 & 2.007 & 2.020 & 2.025 & 2.027 & 2.009 & 0.045 \\
\hline & 99.67 & 2.113 & 2.135 & 2.102 & 2.123 & 2.102 & 2.105 & 2.117 & 2.122 & 2.132 & 2.134 & 2.119 & 0.032 \\
\hline \multirow{4}{*}{$\mathrm{F}$} & 84.19 & 1.824 & 1.842 & 1.839 & 1.857 & 1.780 & 1.803 & 1.834 & 1.835 & 1.836 & 1.920 & 1.835 & 0.140 \\
\hline & 89.43 & 1.937 & 1.957 & 1.939 & 1.959 & 1.917 & 1.917 & 1.935 & 1.949 & 1.956 & 1.975 & 1.942 & 0.058 \\
\hline & 95.40 & 2.066 & 2.087 & 2.055 & 2.076 & 2.045 & 2.062 & 2.066 & 2.081 & 2.090 & 2.091 & 2.073 & 0.046 \\
\hline & 98.94 & 2.143 & 2.165 & 2.122 & 2.143 & 2.125 & 2.125 & 2.133 & 2.136 & 2.147 & 2.151 & 2.136 & 0.026 \\
\hline \multirow{4}{*}{ G } & 85.41 & 1.877 & 1.896 & 1.883 & 1.902 & 1.861 & 1.875 & 1.891 & 1.908 & 1.926 & 1.927 & 1.898 & 0.066 \\
\hline & 90.60 & 1.991 & 2.011 & 1.984 & 2.004 & 1.964 & 1.966 & 1.969 & 2.008 & 2.017 & 2.019 & 1.991 & 0.055 \\
\hline & 95.33 & 2.095 & 2.116 & 2.075 & 2.096 & 2.058 & 2.061 & 2.070 & 2.081 & 2.089 & 2.111 & 2.078 & 0.053 \\
\hline & 98.53 & 2.166 & 2.187 & 2.132 & 2.153 & 2.134 & 2.144 & 2.147 & 2.149 & 2.149 & 2.157 & 2.147 & 0.023 \\
\hline
\end{tabular}

3) The samples with higher powdery clay particles content tend to have obvious expansion due to immersion when the degree of compaction is very high, although the results measured with cutting ring method are within the range of true values of the dry density after immersion, but have a quite difference with the range of true values of the dry density before immersion, indicating that this method is also not suitable for this.

4) Except the special circumstances described above, most of the measured results (average values) are within the range of true values of the dry density before immersion or have a little difference, most of which are less than $0.015 \mathrm{~g} / \mathrm{cm}^{3}$, especially when the degree of compaction is higher, such as more than $90 \%$, and the powdery clay particles content is "moderate". Taking into account that degree of compaction of the detection objects in actual work is generally high, mostly about $94 \%$; and the time from the beginning of immersion to the completion of the test is relatively short, mostly within 30 minutes, based on appropriate increase of parallel tests, this method has more general applicability, for the formed aeolian sand roadbed with dry compaction process, the measured results can basically meet the needs of the project.

\section{Conclusion}

1) There is both expansion and sinking of the deformation after immersion when the aeolian sand in the Gurbantunggut desert is within the range of obvious effect of dry compaction (powdery 
clay particles content is less than or equal to $40 \%$ ). The lower the compaction degree is, the more obvious the sinking will be; and the more the powdery clay particles content is, the more obvious the expansion will be. Under the influence of these two effects, the deformation quantity of most samples is not large except for special cases, especially when the content of powdery clay particles is relatively "moderate", the deformation quantity and the change is relatively small when the degree of compaction is different.

2) The measured results of the cutting ring method are quite volatile, and the measured density difference of the same sample can be above $0.1 \mathrm{~g} / \mathrm{cm}^{3}$, but the most are still within $0.06 \mathrm{~g} / \mathrm{cm}^{3}$. While for different samples, the difference is larger when the degree of compaction is lower and the content of the powdery clay particles is higher. In addition, most of the testing results (average values) are within the true value range or have a small difference, most of which are less than $0.015 \mathrm{~g} / \mathrm{cm}^{3}$, especially when the degree of compaction is higher, for example when it is more than $90 \%$, and the powder content is "moderate"; if using this method to measure the aeolian sand roadbed formed by dry compaction process, the measured results can basically meet the needs of the project.

\section{Acknowledgments}

This work was supported by the Western Traffic Construction Technology Project of the Ministry of Communications(2001 318797 09).

\section{References}

[1] Jin Chang-nin,Li Zhi-nong,Chen Jie,et al.Density of wind-blown sand measured by immerseon wetting and ring sampler[J].Highway,2005(12):128-132. (In Chinese)

[2] Jin Chang-ning, Zhang Yu-hong, LI Sen, et al. Influence of change of granule on compaction features of wind-laid sand[J]. Journal of highway and transportation research and development, 2008,25(10):36-40. (In Chinese)

[3] Liu Yang, Zhou Jian, Wu Shunchuan. Micro-numerical simulation of cyclic biaxial test:results of loose sand[J].Chinese journal of geotechnical engineering,2007,29(7):1035-1041. (In Chinese)

[4] Chi Mingjie, Zhao Chenggang, Li Xiaojun. Stress-dilation mechanism of sands[J].China civil engineering journal, 2009,42(3):99-104. (In Chinese)

[5] Zhang Jianmin.Reversible and irreversible dilatancy of sand[J].Chinese Journal of Geotechnical engineering,2000,22(1):12-17. (In Chinese)

[6] Chang Zai,Yang Jun,Cheng Xiao-hui.Granular mechanical analysis of the strength and dilatancy of sands[J]. Engineering mechanics,2010,27(4):95-104. (In Chinese)

[7] Jin Chang-ning, Zhang Yu-hong.Study on the influence of powdery clay particles on the bearing ratio of aeolian sand[J].Journal of China \& foreign highway, 2012,32 (6):60-64. (In Chinese)

[8] Jin Chang-ning, Zhang Yu-hong. Preliminary study on the effect of powdery clay particles content on the stability of aeolian sand water[J]. Journal of China \& foreign highway,2013,33 (4):255-258. (In Chinese)

[9] Jin Chang-ning, Zhang Yu-hong. Shear deformation characteristics of aeolian sand in Taklamakan desert[J]. Journal of China \& foreign highway,2013,36 (1):27-31.(In Chinese)

[10] JTG E40-2007 Test Method of Soils for Highway Engineering[S].(In Chinese) 